\title{
Rainwater Management of Ventilated Facades: Impact of Joint Width and Cavity Size
}

\author{
Stéphanie Van Linden and Nathan Van Den Bossche \\ Ghent University, Faculty of Engineering and Architecture, Building Physics Group, Sint- \\ Pietersnieuwstraat 41 B4, Ghent, Belgium, stephanie.vanlinden@ugent.be
}

\begin{abstract}
During a rain event, most of the raindrops reaching the facade either splash back or run off the exterior surface of the facade. However, it is evident that also a portion of the water infiltrates through the open joints of a ventilated facade. The infiltrated water may either be drained in the cavity to the bottom of the wall or reach the insulation layer. If there are any deficiencies present in the insulation layer or at the connection of the brackets, the infiltrated water might introduce problems. Additionally, if the cavity is not able to drain all the infiltrated water or adhered droplets to one of the cavity surfaces do not dry out, moisture problems might occur. Experiments were conducted to determine the infiltration rate through ventilated facades with open joint widths of $5 \mathrm{~mm}, 10 \mathrm{~mm}$ and $15 \mathrm{~mm}$ and cavity widths ranging from $190 \mathrm{~mm}$ to $40 \mathrm{~mm}$. It was observed that the amount of infiltrating water was larger for larger joints widths. Due to the larger kinetic energy of the drops flowing through the larger joint widths, the drops were able to reach the exterior surface of the insulation layer, even for large cavity widths. The results from the experimental assessment were used as input parameters for hygrothermal simulations to determine the risk of moisture problems.
\end{abstract}

Keywords: Water Infiltration, Drainage, Ventilated Facades, Moisture Loads.

\section{Introduction}

Ventilated facades are usually designed according to the open rainscreen principle to control rainwater penetration (Garden, 1963). The external cladding, which usually consists of independent facade panels, is supposed to keep out most of the rain. Evidently, also a portion of the driving rain infiltrates through the open joints between the facade panels and reaches the air cavity behind the external cladding. This cavity acts as a capillary break and drains the infiltrated water to the bottom of the wall where it may flow back to the exterior through drainage holes. The air barrier at the interior side of the facade restricts the airflow through the wall. Combined with the open joints between the facade panels, the pressure difference over the cladding is minimized. This reduces the pressure difference acting as one of the main driving forces for water to infiltrate (Suresh Kumar, 2000). Other forces that may affect water infiltration through joints are surface tension, capillarity, kinetic energy and gravity. Experiments conducted by Mas et al., (Mas, Gutiérrez, Gil, Gil, and Galvan, 2011) revealed that for joint widths larger than $8 \mathrm{~mm}$, gravity and kinetic energy are the main forces driving rain through the joints, capillarity and surface tension having less importance.

For the same weather conditions, the amount of infiltrating water depends on the geometry of the joints and the material characteristics. When raindrops infiltrate, they are either drained to the bottom of the wall or they may reach the drainage layer at the back of the cavity dependent 
on the cavity size and the geometry of the joints. If there are any deficiencies present at the drainage layer or at the connection of the brackets, the infiltrated water might introduce problems. Additionally, if the cavity is not able to drain all the infiltrated water or if adhered water drops to one of the cavity surfaces do not dry out, moisture problems might occur. However, the amount of experimental work that quantifies the portion of infiltrating water through ventilated facades and the portion of water reaching the drainage layer at the back of the cavity, is very limited.

Recatala et al., (2017) assessed the watertightness performance of a full-scale ventilated facade specimen with joint widths of $10 \mathrm{~mm}$. Laboratory experiments showed that the airtightness level of the wall did not have an impact on the infiltration rates as pressure moderation over the external cladding was achieved for both leaky and sealed constructions. The applied spray rate, however, did have a significant impact on the infiltration rate. A parabolic correlation was obtained between both parameters. It was observed that when a lot of water was running down the external cladding, the water runoff film prevented driving rain drops from infiltrating through the open joints and bounced and splashed off the surface instead. The results also showed that the infiltration rate of water through the horizontal joints was significantly larger than the infiltration rate through the vertical joints. Also the impact of the horizontal joints on the amount of water reaching the drainage layer at the back of the cavity was larger compared to the impact of vertical joints. The splattering effect of raindrops in the joints and onto the brackets caused additional raindrops to reach the drainage layer. However,

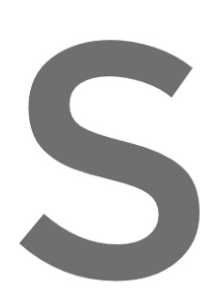
most of the infiltrated

impinging water on the situated $10 \mathrm{~cm}$ behind proposes a default penetration more research on the a different wall configurations is necessary.
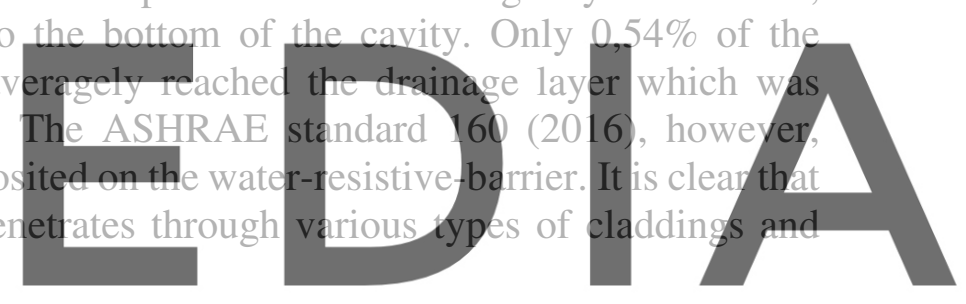

The objective of this study is to assess the impact of the joint width and cavity size of a

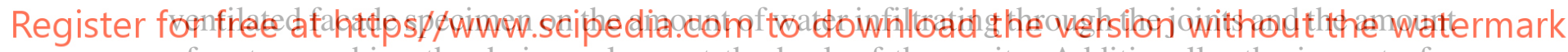
of water reaching the drainage layer at the back of the cavity. Additionally, the impact of a panel installed out of plane of the exterior surface on the infiltration rate was assessed. The results from the experimental assessment were used as input parameters for hygrothermal simulations to determine the risk of moisture problems.

\section{Test Setup and Methodology}

\subsection{Test Setup}

The impact of joint width, cavity size and construction errors on the infiltration rates through ventilated facades was evaluated by means of five test specimens. Each test specimen was mounted in a steel frame with dimensions 2390 x $1070 \mathrm{~mm}$ and incorporated 24 fibre cement boards. These boards were screwed onto vertical timber studs with a cross-section of $38 \times 90$ $\mathrm{mm}$. The vertical studs were positioned at the vertical joints between the facade panels. Flashing was applied between the studs and the facade panels as recommended by the manufacturer to avoid water being absorbed by the wood studs. The vertical studs were affixed to a wood frame, simulating the structural wall, by means of threaded rods. In between the vertical studs and the 
wood frame a PMMA panel was installed, simulating the drainage layer which in case of ventilated facades usually is the insulation layer. The PMMA panel could be moved further away or closer to the facade panels in order to vary the cavity width. The fibre cement boards had a thickness of $8 \mathrm{~mm}$ and a width and length of $300 \mathrm{~mm}$. The width of the boards at the sides of the specimens was dependent on the applied joint width.
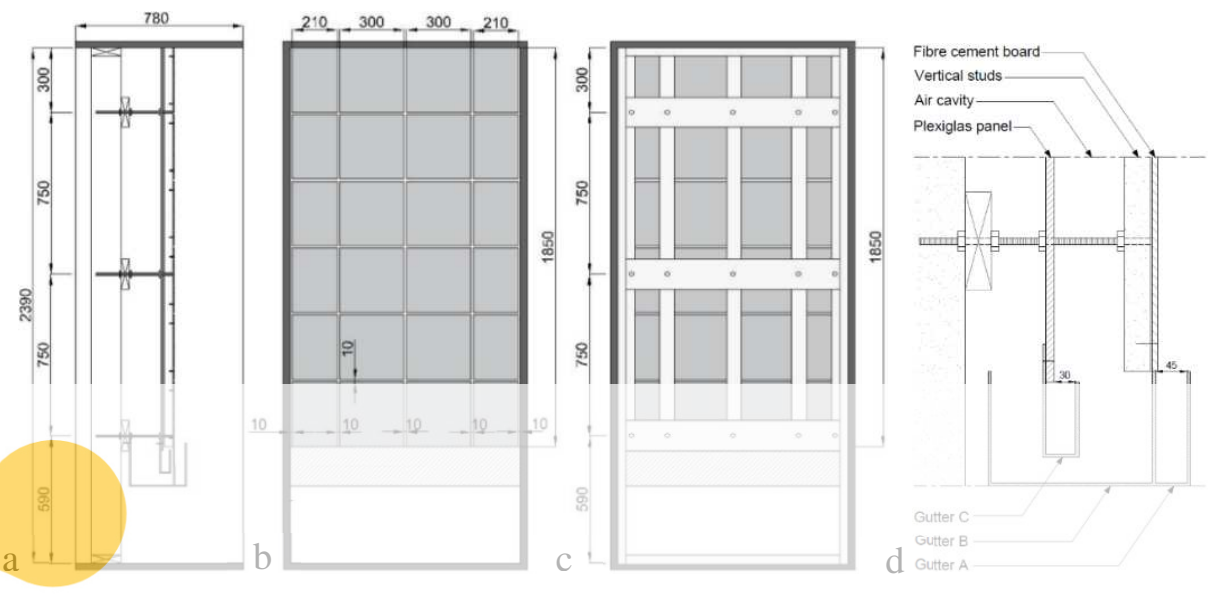

Figure 1. a) Cross section, b) Front view, c) Rear view of test setup 2, d) Detailed cross section gutter system.

The specimens evaluated by Recatala et al., (2017) had a joint width of $10 \mathrm{~mm}$. The same width was chosen as the standard joint width in this study. Additionally, joint width of $5 \mathrm{~mm}$
was evaluated, as Mas et al., (2011) stated that the impact of surface tension and capillarity
increased for joint widths smaller than $8 \mathrm{~mm}$. The largest evaluated joint width was $15 \mathrm{~mm}$.
The smallest evaluated cavity width was 40 mm as this was the combined thickness of the
vertical studs and the flashing. The largest evaluated cavity width was $190 \mathrm{~mm}$ as it was observed that no significant differences were measured for a cavity width of $160 \mathrm{~mm}$ and

Register for ffmee at https//www.scipedia.com to download. the version without the watermark Three gutters were installed at the bottom of each specimen: gutter A collected the water which flowed downward at the exterior side of the facade panels during the test or splashed back up to $45 \mathrm{~mm}$ in front of the panels, gutter B collected the water which flowed downward at the back of the facade panels, the vertical studs and in the drainage cavity, and gutter $\mathrm{C}$ collected the water which flowed downward at the PMMA panel and up to $30 \mathrm{~mm}$ in front of the panel. In case a cavity width of $40 \mathrm{~mm}$ was applied, gutter B only collected the water that ran off the interior side of the facade panels and gutter $\mathrm{C}$ collected the remaining portion of water that reached the cavity.

\subsection{Test Procedure}

Water was sprayed onto the test specimens by means of a spraying rack with full cone nozzles which were installed at the top of the specimens and at a horizontal distance of $250 \mathrm{~mm}$. A constant spray rate of $120 \mathrm{l} / \mathrm{h}$ was applied. No pressure difference was applied to the external cladding as Recatala (2017) already observed that pressure equalization was achieved for both leaky and sealed specimens. The water collected by the gutters was weighed both during and after the test by means of weighing scales with an accuracy of $\pm 0,1 \mathrm{~g}$. Water was sprayed for 400 seconds or until the infiltration rate for all gutters was constant for a significant amount of 
time. The pattern of water droplets which adhered to the PMMA panel after the test was visually evaluated. The repeatability of the test procedure was evaluated by conducting the same experiment at least two times.

\section{Experimental Results and Discussion}

\subsection{Impact of Joint and Cavity Width}

Figure 2 shows the percentage of water collected by gutter $\mathrm{A}, \mathrm{B}$ and $\mathrm{C}$ relative to the total amount of collected water. The tests were conducted for different cavity widths ranging from 4 $\mathrm{cm}$ to $19 \mathrm{~cm}$ and joint widths of $5 \mathrm{~mm}, 10 \mathrm{~mm}$ and $15 \mathrm{~mm}$ for respectively specimen 1,2 and 3. As the timber studs were situated at the vertical joints, the collected water only infiltrated through the open horizontal joints.

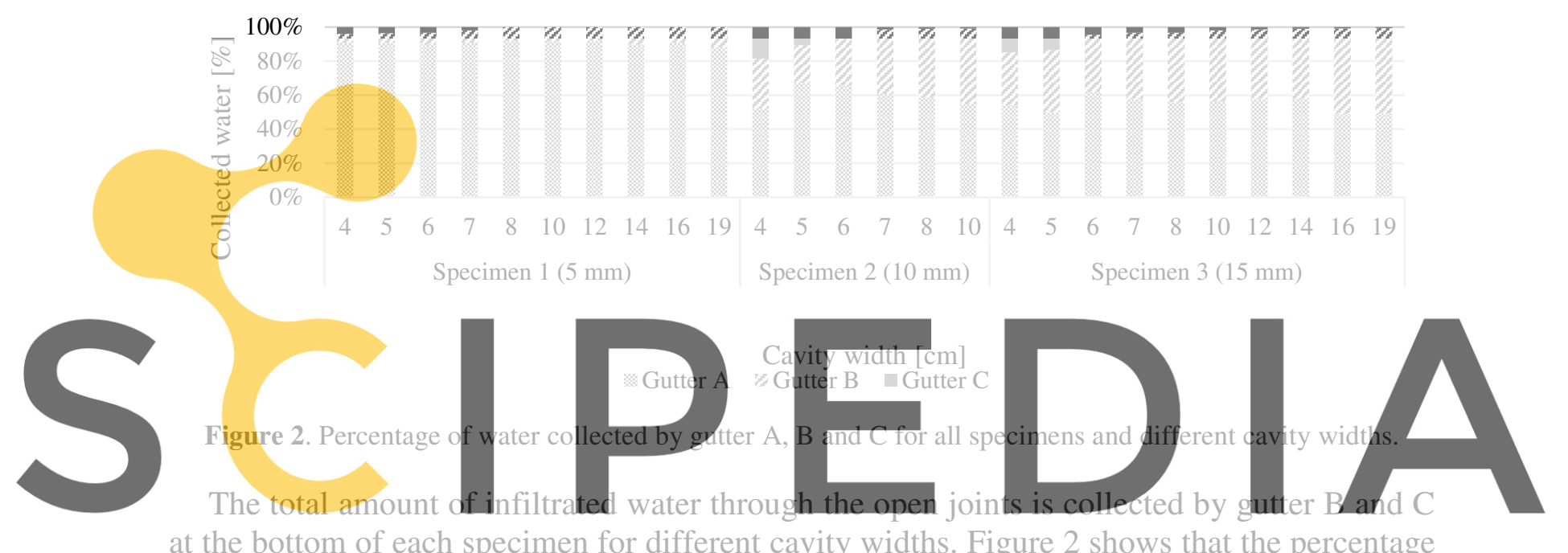

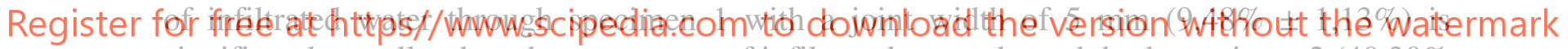
significantly smaller than the percentage of infiltrated water through both specimen $2(40,30 \%$ $\pm 5,89 \%)$ and $3(45,15 \% \pm 4,29 \%)$ with respective joint widths of 10 and $15 \mathrm{~mm}$. Raindrops may either infiltrate due to kinetic energy, gravity, surface tension or capillarity. Also some drops might stagnate on top of the facade panels. In case other drops impinge on these stagnating drops, water may infiltrate due to splattering. Raindrops may also bounce on top of the facade panels or splash open. The larger percentage of infiltrated water through larger joint widths implies that more raindrops are able to flow freely through the larger joints and therefore the kinetic energy of the water drops has a larger impact on the infiltration rates. In case of smaller joint widths $(5 \mathrm{~mm})$ the effect of capillarity and surface tension becomes more important and water bridging of the joint is observed at some locations. Water drops are no longer able to flow freely through the joints and splatter onto the occluded joints, significantly reducing the infiltration rate. The increase in infiltration percentage from $10 \mathrm{~mm}$ joint widths to $15 \mathrm{~mm}$ joint widths, however, is not significant.

The reduced impact of kinetic energy on the infiltration rate for smaller joint widths is also apparent when the amount of water reaching the back of the cavity and collected by gutter $\mathrm{C}$ is compared for the different specimens. For specimen 1 with a joint width of $5 \mathrm{~mm}$, water reaches the back of the drainage cavity for cavity widths of $7 \mathrm{~cm}$ and smaller $(2,05 \%$ of collected 
water). In contrast, water was already collected in gutter $\mathrm{C}$ for specimen 2 with a cavity width of $10 \mathrm{~cm}(0,88 \%$ of collected water) and for specimen 3 even for cavity widths of $19 \mathrm{~cm}(0,82 \%$ of total collected water). For a cavity width of $5 \mathrm{~cm}$ and $4 \mathrm{~cm}$, a constant water runoff was visible at the PMMA panel for both specimen 2 and 3 . In case of a cavity width of $4 \mathrm{~cm}, 18,71 \%$ and $14,80 \%$ of the total amount of collected water was collected by gutter $\mathrm{C}$ for respectively specimen 2 and 3. For specimen 1, no runoff was present for these cavity widths at the PMMA panel, only some drops reached the panel, in particular at the height of the spraying rack. The collected water in gutter $\mathrm{C}$ of specimen 1 was mainly attributed to water running off the vertical studs instead of water reaching the PMMA panel.

The results obtained by Recatala et al. (2017) are within the same order of magnitude as the results obtained in this study. For a cavity width of $10 \mathrm{~cm}$ and a joint width of $10 \mathrm{~mm}$ Recatala measured an infiltration rate at the drainage layer of 0,0029 1/min.m, compared to an infiltration rate of $0,00241 / \mathrm{min} . \mathrm{m}$ in this study.

\subsection{Impact of Construction Errors}

Figure 3 shows the percentage of water collected by gutter A, B and C for specimens 2, 4 and 5. Specimen 4 and 5 incorporated one facade panel installed respectively $5 \mathrm{~mm}$ and $10 \mathrm{~mm}$ out of the exterior plane. The joint width applied to all specimens was $10 \mathrm{~mm}$. The tests were conducted for cavity widths of 4,8 and $12 \mathrm{~cm}$.
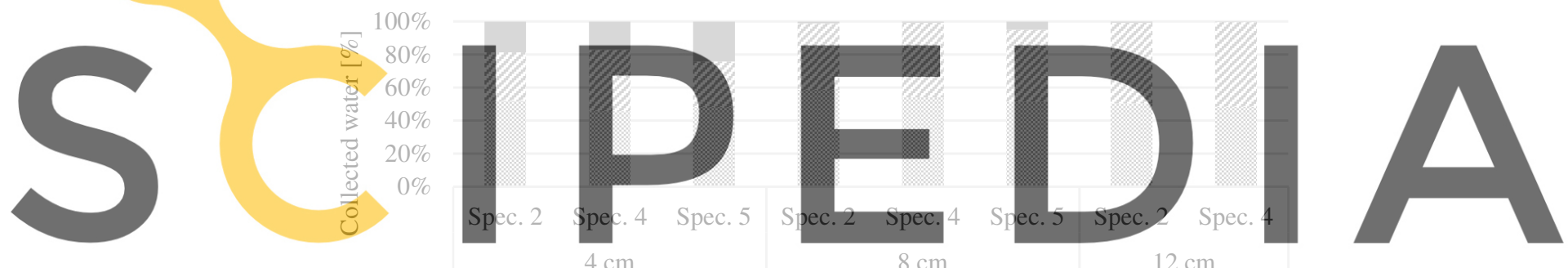

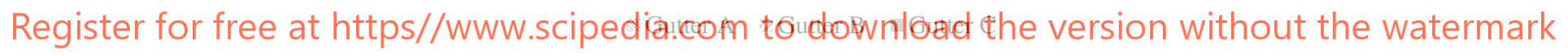

Figure 3. Percentage of water collected for specimen 2 (no error), specimen 4 ( 5 mm error) and specimen 5 (10 mm enor) at different cavity widths.

Although a larger opening was present through which water could infiltrate freely due to the out of plane installed panels, only a small increase in the percentage of infiltrated water was measured. As the panel of specimen 4 was only installed $5 \mathrm{~mm}$ out of plane and the total thickness of the facade panels was $8 \mathrm{~mm}$, there was still an overlap between the other panels and the panel out of plane. This prevented downward flowing drops from infiltrating due to gravity. Water drops instead bounced, splashed or stagnated on the top of the out of plane installed panel, with only a small increase of the infiltrated water as a result. When the panel was installed $10 \mathrm{~mm}$ out of plane (specimen 5), downward flowing water drops were able to infiltrate due to gravity. As the panels were installed vertically out of plane, however, these infiltrated drops were able to flow further down along the exterior surface of the underlying panel. Due to the larger horizontally oriented open joint, water drops could flow more freely through the opening and due to kinetic energy they were able to reach further into the cavity resulting in larger percentages of water collected in gutter $\mathrm{C}$ of specimen 5 . 


\section{Hygrothermal Evaluation}

As observed in the laboratory experiments, water drops are able to infiltrate through the open joints of ventilated facades and reach the insulation layer. In case a small cavity width is applied and deficiencies are present at the insulation layer, e.g. an open joint between two insulation panels, raindrops are able to flow through this open joint. These raindrops can either stagnate on top of the insulation panel and dry out again or flow further inward and reach the brick layer of the wall. This might cause mould growth or a reduced thermal performance of the insulation. The risk of both phenomena was assessed by means of the hygrothermal simulations. A common used ventilated facade construction in Belgium was modelled in WUFI PRO 5.3. A worst-case scenario was simulated, i.e. a small cavity width of $40 \mathrm{~mm}$ was applied and it was assumed that all infiltrating water reached the brick layer behind the insulation. The construction had a south-west orientation and a height up to $10 \mathrm{~m}$. The material properties used in the simulations can be found in Table 1 . The simulations start at October $1^{\text {st }}$ and run for a period of 3 years. A time step of 1 hour was applied.

Table 1. Material properties (based on WUFI material database).

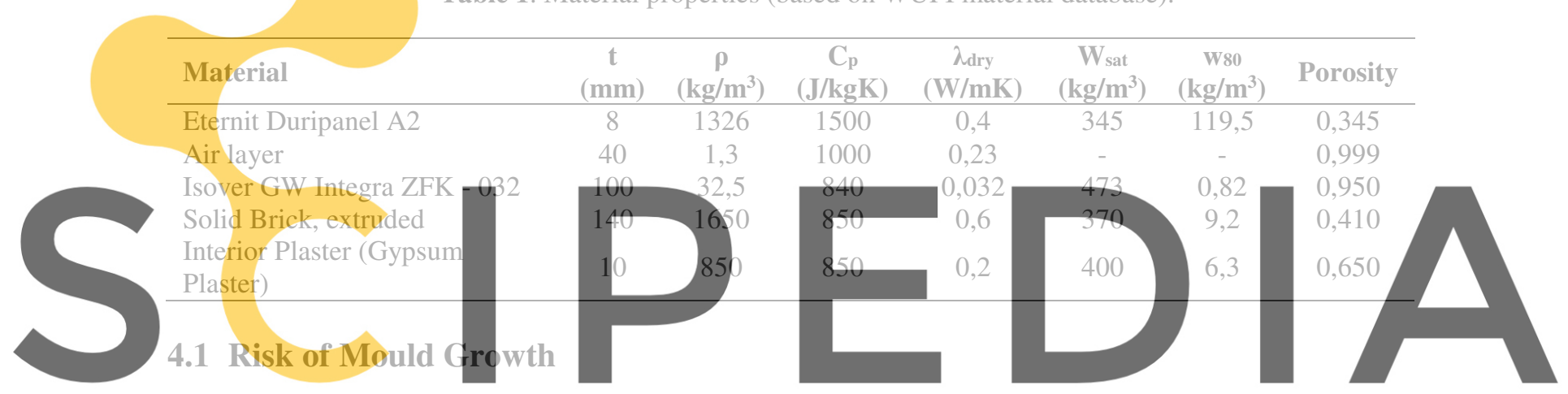

In case raindrops are able to reach the brick layer of the wall assembly, the raindrops will be

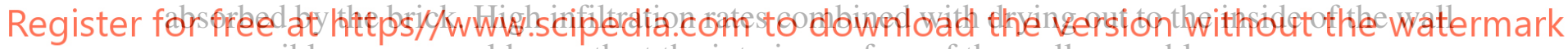
can possibly cause mould growth at the interior surface of the wall assembly.

The risk of mould growth is assessed by means of the isopleth model by Sedlbauer which is implemented in WUFI. The isopleth curves separate favourable from unfavourable temperature and relative humidity conditions for mould growth for different substrate groups (Sedlbauer, 2001). A moisture source was implemented in the brick layer of the modelled wall assembly.

In case $15 \%$ of the driving rain reaches the brick layer and the air change rate in the air cavity is $10 \mathrm{~h}^{-1}$, some data points are situated above the LIM I curve of Sedlbauer, meaning that there is a risk of mould growth for biologically recyclable materials. If the infiltration percentage is increased to $20 \%$ of the driving rain, the limiting isopleth for biologically adverse recyclable building materials (LIM II) is exceeded for a longer period and the risk of mould growth at the interior surface is significant. The results from the experimental study showed the highest infiltration percentages (collected by gutter $\mathrm{C}$ ) for a ventilated facade with a joint width of 10 $\mathrm{mm}$ and a cavity width of $4 \mathrm{~cm}$, i.e. $18,71 \%$. However, in reality only a portion of the infiltrated water will reach the insulation layer and a small percentage will infiltrate toward the brick layer. It can therefore be stated that the risk of mould growth is limited for the assessed ventilated facade. 
If the air change rate is increased from $10 \mathrm{~h}^{-1}$ to $1000 \mathrm{~h}-1$, the limiting isopleth for biologically adverse recyclable building materials is still exceeded for an infiltration percentage of $20 \%$. This implies that in case raindrops are able to reach the brick layer behind the insulation, increasing the air change rate only has a limited impact on the mould growth.
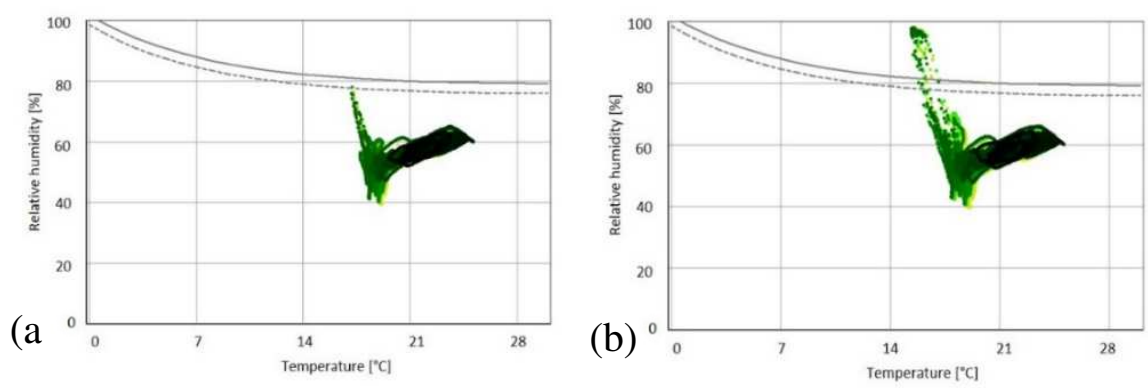

Figure 4. Isopleths on the interior surface, (a) infiltration percentage of $15 \%$ and (b) infiltration percentage of $20 \%$.

\subsection{Impact on Heat Flux}

As the thermal conductivity of the insulation is moisture-dependent, infiltrating water in the wall assembly will have an impact on the heat losses through the wall assembly. As insulation is a non-hygroscopic material, raindrops infiltrating through deficiencies in the insulation layer, will either dry out or flow further inward. In case of a worst-case scenario, infiltrating raindrops might reach the brick layer behind the insulation. and accumulation of n assembly. This may cau

Table 2. Impact of infiltration percentage in brick
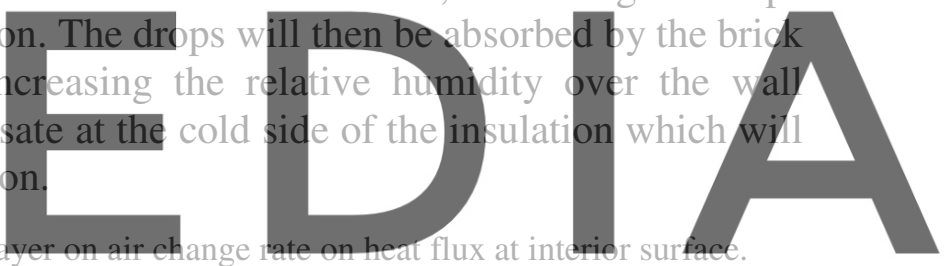

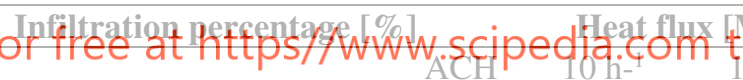

No moisture source

1

5

10

15

20

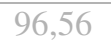

99,74

112,30

129,30

149,60

172,92

$\begin{array}{ll}100,93 & 102,55 \\ 114,22 & 116,14 \\ 129,97 & 132,36 \\ 144,00 & 147,05 \\ 154,46 & 158,22\end{array}$

e yerease relative to nq moisture

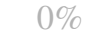

$3,29 \%$

$16,66 \%$

$33,91 \%$

$54,93 \%$

$79,08 \%$
$4,00 \%$

$20,38 \%$

$39,79 \%$

$57,07 \%$

$69,97 \%$
$3,35 \%$

$17,04 \%$

$33,38 \%$

$48,19 \%$

In case a moisture source of $1 \%$ of the driving rain is implemented in the middle of the brick layer, an increase of $3,29 \%$ of the heat flux at the interior surface is measured compared to the case with no moisture source. This increase in total heat flux is primarily attributed to the increase of the latent heat flow associated with vapour diffusion at the surface. In case the latent heat flow is excluded, the increase in heat flux is $0,04 \%$ for a moisture source of $1 \%$ of the driving rain. In case a moisture source of $10 \%$ of the driving rain is applied, an increase of the total heat flux at the interior surface of $34,62 \%$ is measured. Excluding the latent heat flow, the moisture source causes an increase of the total heat flux of $3,41 \%$. In case of a moisture source of $10 \%$ of the driving rain, the insulation layer still dries out over a period of one year. In case however, a moisture source of $15 \%$ of the driving rain is applied, i.e. all the infiltrating water 
reaches the brick layer behind the insulation, the water in the insulation layer does not evaporate over a period of 1 year and instead accumulates. Increasing the air change rate in the air cavity in front of the insulation, increases the air velocity at the insulation layer, resulting in an improved drying of the wet insulation and therefore a reduction of the heat flux.

\section{Conclusions}

An experimental study was conducted to assess the impact of the joint width and the cavity size of a ventilated facade specimen on the amount of water infiltrating through the open joints and the amount of water reaching the drainage layer at the back of the cavity. Additionally, the impact of a panel installed out of plane of the exterior surface on the infiltration rate was assessed. The results from the experimental assessment were used as input parameters for hygrothermal simulations to determine the risk of moisture problems.

The experimental study showed that the infiltration percentage of raindrops through open joints of $5 \mathrm{~mm}(9,48 \% \pm 1,13 \%)$ was significantly smaller compared to the infiltration percentage through joints of $10 \mathrm{~mm}(40,30 \% \pm 5,89 \%)$. Raindrops infiltrating through the 5 $\mathrm{mm}$ joints of the ventilated facade reached the drainage layer and up to $3 \mathrm{~cm}$ in front of the drainage layer for cavity widths of $7 \mathrm{~cm}$ and smaller. For joint widths of $10 \mathrm{~mm}$ and $15 \mathrm{~mm}$ however, water was already collected $3 \mathrm{~cm}$ in front of the drainage layer for cavity widths of respectively $10 \mathrm{~cm}$ and $19 \mathrm{~cm}$ and a runoff film was present at the drainage layer for cavity widths of 4 and $5 \mathrm{~cm}$. Hygrothermal simulations showed that the risk of mould growth at the

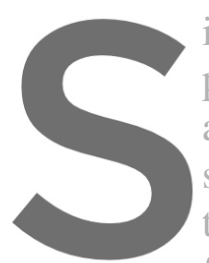
interior surface of percentages. The impac a cavity of $40 \mathrm{~mm}$ is side of the wall throug the driving rain in the $b$ flux of 3,29
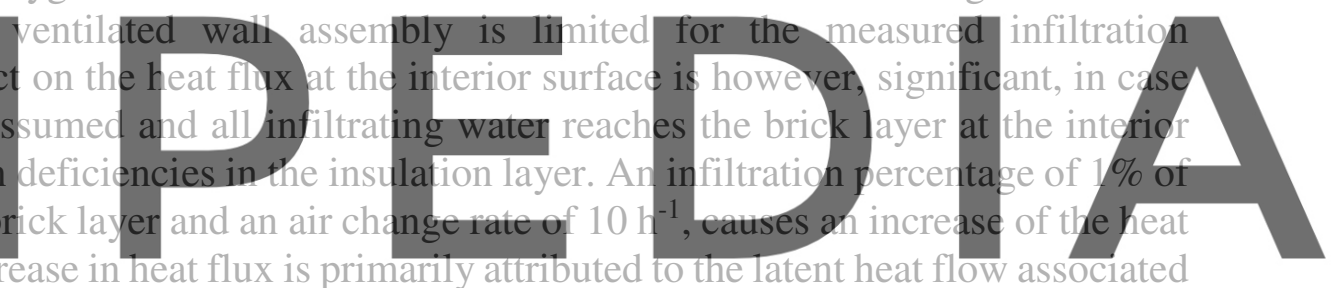
with vapour diffusion at the surface. In case of an infiltration percentage of $10 \%$, the increase

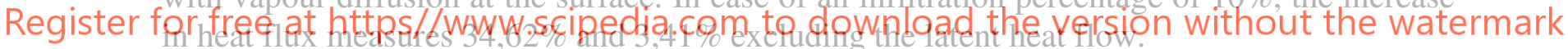

\section{ORCID}

Stéphanie Van Linden: https://orcid.org/0000-0002-4102-2076

Nathan Van Den Bossche: https://orcid.org/0000-0002-8738-7249

\section{References}

Arce Recatala, M., Garcia Morales, S. and Van Den Bossche, N. (2017). Experimental assessment of rainwater management of a ventilated façade. Journal of Building Physics, 1-30.

ASHRAE. (2016). Ashrae Standard 160-2016 - Criteria for moisture-control design analysis in buildings. Atlanta.

Garden, G. (1963). Rain penetration and its control. Canadian Building Digest, 40, 401-404.

Mas, A., Gutiérrez, J., Gil, E., Gil, A. and Galvan, V. (2011). Design and construction recommendations to improve impermeability in rainscreen walls built with natural stone coverings. Construction and Building Materials, 1753-1761.

Sedlbauer, K. (2001). Prediction of mould manifestation on and in buildings. Stuttgart: University of Stuttgart.

Suresh Kumar, K. (2000). Pressure equalization of rainscreen walls: a critical review. Building and Environment, 161-179. 